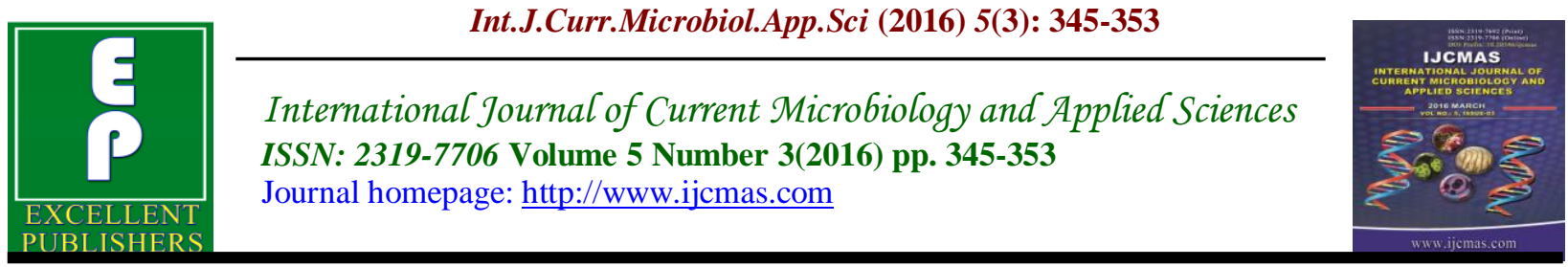

Original Research Article

http://dx.doi.org/10.20546/ijcmas.2016.503.041

\title{
Screening of Tyrosinase Producing Soil Actinomycetes from Shirala Region of Maharashtra, India
}

\author{
Gare Sandip Subhash $^{1 *}$, D.D. Karad ${ }^{2}$ and S.W. Kulkarni ${ }^{3}$ \\ ${ }^{1}$ Department of Microbiology, Vishwasrao Naik Art's, Commerce and Baba Naik Science \\ Mahavidyalaya, Shirala 415408, Dist-Sangli M.S, India \\ ${ }^{2}$ Departments of Microbiology and Research Center, Shri Shivaji Mahavidyalaya, \\ Barshi-413 411, Dist-Solapur, MS, India \\ ${ }^{3}$ Research Department of Microbiology, Shriman Bhausaheb Zadbuke Mahavidyalaya, \\ Barshi 413 401, Dist-Solapur M.S, India \\ *Corresponding author
}

\begin{abstract}
A B S T R A C T
Keywords

Actinomycetes,

Genus,

Streptomyces,

Tyrosinase,

Screening.

Article Info

Accepted:

15 February 2016

Available Online:

10, March 2016

A total seven soil samples were collected from the Shirala region Dist-Sangli. The total 70 Actinomycete isolates were obtained from soil by performing serial dilution technique and using Glycerol asparagine agar supplemented with Cycloheximide $(100 \mu \mathrm{g} / \mathrm{ml})$. Actinomycete isolates were primarily identified to genus level on the basis of their microscopic and cultural characteristics. Biochemical and other characters were used to identify isolates to species level. A total 70 Actinomycete isolates were identified by using modified DOS based MICRO-IS software such as PIBWin. Out of 70 Actinomycete isolates total $82.85 \%$ isolates were belonged to genus Streptomyces, $10 \%$ isolates were belonged to genus Streptoverticillum, $2.8571 \%$ isolates were belonged to Nocardia, $2.8571 \%$ isolates were belonged to genus Micromonospora and rest of the $1.4285 \%$ isolate were belonged to Actinomadura. The primary screening of 70 isolates for tyrosinase production were carried out and isolates were showed positive tyrosinase activity.
\end{abstract}

\section{Introduction}

The word actinomycete was taken from the Greek. It has made from two different words such as "atkis" (a ray) and "mykes" (fungus), possess characteristics of both bacteria and fungi. Actinomycetes bear almost distinctive features than bacteria and fungi, so they fixed into separate class. Actinomycetes are aerobic, spore forming, Gram positive bacteria grouped as branching unicellular organisms, belonging to order actinomycetales highlighted with substrate and aerial mycelial growth (Lechevalier and Lechevalie, 1981). Actinomycetes reproduce either by fission or by means of special spores or conidia. They possess high $(\mathrm{G}+\mathrm{C})$ content in their DNA which is above $55 \mathrm{~mol}$ percent. The evidences of $16 \mathrm{~s}$ ribosomal cataloguing and DNA: rRNA pairing studies 
suggested that phylogenetic relationship among the group of actinomycetes (Goodfellow and Williams, 1983; KornWendisch and Kutzner , 1992). The domain bacteria has been currently proposed with 18 major lineages out of them actinomycetes represent one of the largest taxonomic unit. (Ventura, et al., 2007) In soil actinomycetes from thread like filaments and which are most abundant organisms. The characteristic earthy smell of freshly turned healthy soil is due to hypae produced at the time of growth.(Sprusansky, et al., 2005) The actinomycetes are found in various habitats in nature (George, et al, 2012) and most prominent group of microbes distributed throughout the natural ecosystems around the world. (Srinivasan, et al., 1971) They are initially represented as soil inhabitants. (Kuster, 1968)

Microbial secondary metabolites have great interest all over the world. Around 23,000 bioactive secondary metabolites are reported throughout the world in which 10,000 are produced only by actinomycetes, hence contributing $45 \%$ of all bioactive microbial metabolites discovered and among actinomycetes, near about 7,600 compounds are produced by Streptomyces species. (Berdy, 2005) Their metabolic potential offers a strong area of research. Accordingly, the role of actinomycetes in biotechnology and medicine is well known and these industries are always looking for novelty bioactive compounds.

The value of the world enzyme market has increased steadily from $£ 110$ million in 1960 to $£ 200$ million in $1970, £ 270$ million in 1980, £1 000 million in 1990 and over £2 000 million in 2010. Food and beverage enzymes represented the largest sector of the industrial enzymes market in 2010, with a value of $£ 750$ million, and the market for enzymes for technical applications (including diagnostic applications, research and biotechnology) accounted for a further $£ 700$ million. Estimates of future demand are in the range of $£ 4000-5000$ million between 2015 and 2016, growing at a rate of 6-7\% annually. The developing economies of the Asia Pacific Region, the Middle East and Africa are now seen to be emerging as the fastest growing markets for industrial enzymes.

Tyrosinase (EC 1.14.18.1) is a coppercontaining enzyme that have both monophenolase or cresolase and diphenolase or catecholase activity in which monophenolase or cresolase activity of an enzyme tyrosinase expressed by catalyzing the $o$-hydroxylation of monophenols to the corresponding catechols and diphenolase or catecholase catalysing the oxidation of diphenols or catechols to the corresponding $o$-quinones. The enzyme can be found in a wide variety of organisms, ranging from prokaryotes to mammals. Tyrosinase can take part in biosynthesis of melanin in which monophenolase or cresolase activity of an enzyme tyrosinase can catalyses substrate tyrosine into 3,4-dihydroxyphenylalanin or DOPA (o-diphenol) by ortho-hydroxylation reaction and an enzyme diphenolase or catecholase activity of an enzyme tyrosinase can catalyse substrate 3,4dihydroxyphenylalanin or DOPA into dopaquinone (o-quinone) by oxidation reaction followed by o-quinone turn to melanin pigments through series of enzymatic and nonenzymatic reactions. (Robb, 1984; Whitaker, 1995) Along with tyrosine and L-DOPA numerous other substrates such as phenols and diphenols are converted to corresponding diphenols and quinones respectively by an enzyme tyrosinase. Basically, the monophenol hydroxylase and diphenoloxidase activities of tyrosinase are used in environmental technology for the detoxification of phenolcontaining waste waters and contaminated 
soils as a construction of a biosensor for the detection of phenolic compound. (Dos Santos, et al., 2013) In pharmaceutical industries tyrosinase has been used for the production of $o$-diphenols such as L-DOPA and dopamine for the treatment of Parkinson's disease and also have been reported as a marker in melanoma patients (Gradilone, et al., 2010) and as a target for the activation of prodrugs (Jawaid, et al., 2009) in food industries for modification of food proteins via crosslinking affects. (Monogioudi, et al., 2011) Synthetic melanin is also used for protection against radiation (UV, X-ray, and gamma ray), cation exchangers, drug carriers, antioxidants, antiviral agents, or immunogen. There is considerable information representing the great potential of this enzyme for food, medicine, and agricultural industries as well as for analytical and environmental purposes. (Claus and Filip, 1988)

While most of the studies on actinobacteria have focused on antibiotic production, only few reports have focused on their enzymatic potential. Streptomyces genus were extensively studied because of their capacity to produce antibiotics and enzymes of industrial importance (Bahrim and Negoita, 2007) Bacterial tyrosinase with new features like high-temperature stability, (Kong, et al., 2000) or a broader substrate spectrum (Wang, et al., 2000) open further areas of applications. The tyrosinase from Streptomyces species are non modified monomeric proteins with relatively low molecular mass. These enzymes are secreted to the surrounding medium, where they are involved in extracellular melanin production.

An enzyme tyrosinase has remarkable properties and many applications in different sectors as mentioned above. Different aspects of an enzyme tyrosinase have been so far studied to some extent throughout the world by scientists. Geographically Shirala region is situated at heavy rain fall. No one had reported actinomycetes from this region which can produce tyrosinase. This study focuses on screening of actinomycetes which have ability to produce an enzyme tyrosinase.

\section{Materials and Methods}

\section{Materials}

1. Soil sample- seven soil samples were collected from the villages around Shirala region

Dist.-Sangli, M.S. India and used in this study for isolation of actinomycetes.

2. Glycerol asparagine broth, Glycerol asparagine agar and Cycloheximide.

3. Skimmed milk agar, Tyrosine agar, Peptone yeast extract iron agar, Tyrosine broth and Chloroform.

\section{Methods}

\section{Isolation of Actinomycetes}

The soil samples were collected from the villages around Shirala region Dist.-Sangli, M.S. India and enrichment of soil samples were carried out in Glycerol asparagine broth supplemented with Cycloheximide $(100 \mu \mathrm{g} / \mathrm{ml})$. A 10 -fold serial dilution of the sample was prepared up to $10^{-6}$ and $0.1 \mathrm{ml}$ aliquots of each dilution was inoculated into Glycerol asparagine agar ( $\mathrm{L}$ asparagine0.1g, K2HPO4-0.1g, glycerol- 1\%, trace salt solution- $0.1 \mathrm{ml}$, agar- $2.5 \mathrm{~g}$, distilled water$100 \mathrm{ml} \mathrm{pH-7.4).} \mathrm{To} \mathrm{avoid} \mathrm{the} \mathrm{growth} \mathrm{of}$ fungal contaminant medium were supplemented with Cycloheximide $(100 \mu \mathrm{g} / \mathrm{ml})$. Plates were incubated at room 
temperature $\left(28^{\circ} \mathrm{C}\right)$ and monitored periodically over 5 to 7 days. Pure isolates were transferred on same medium as slants and preserved at $4 \pm 2^{\circ} \mathrm{C}$ for further study.

\section{Identification of Isolates}

Morphological characteristics were studied with cover slip culture technique. Cultural characteristics were recorded on Glycerol asparagine agar medium. Biochemical characters were recorded on the basis of sugar utilization potential, enzymatic activities and growth under inhibitory substances. On the basis of spore mass color, the substrate mycelium color, the shape of the spore chain, morphological and cultural characters of actinomycetes suspected to be Streptomyces were sorted. Biochemical characterisations of Streptomyces producing tyrosinase were carried out.

\section{Primary Screening}

The primary screening of tyrosinase enzyme producing actinomycetes were carried on Skimmed milk plates ( $\mathrm{pH}$ 6.5-7.2); containing peptone-1\%, sodium chloride$0.5 \%$, yeast extract- $0.3 \%$, agar- $2 \%$ and skimmed milk-10\%. All the plates were incubated at $30^{\circ} \mathrm{C}$ for $2-3$ days. After incubation, the plates were observed for the zone of clearness around the colony. The results were interpreted as follows '-' no zone of clearness and ' + ' shows zone of clearness.

\section{Secondary Screening Method}

Tyrosinase enzyme producing Soil actinomycetes were further screened by following different methods like tyrosine agar plate, peptone yeast extract iron agar and tyrosine broth

\section{Tyrosine Agar}

The isolates were streaked on tyrosine agar
( $\mathrm{pH}$ 7) containing Asparagine-0.1\%, Ltyrosine- $\quad 0.5 \%, \quad \mathrm{~K} 2 \mathrm{HPO} 4-0.05 \%$, $\mathrm{MgSO} 4.7 \mathrm{H} 2 \mathrm{O}-0.05 \%$, NaCl-0.05\%, FeSO4.7H2O-0.000001\%, $\mathrm{CuCl} 2.2 \mathrm{H} 2 \mathrm{O}-$ $0.0000027 \%$, CoCl2.6H2O-0.000004\%, Sodium molybdate.2H2O-0.0000025\%, Zinc chloride- $0.000002 \%$, Boric chloride$0.000285 \%$, Manganese chloride 4H2O$0.00018 \%$, Sodium tartarate- $0.000177 \%$ and agar-2\%. All the plates were incubated at $30^{\circ} \mathrm{C}$ for $48 \mathrm{hrs}$ the occurrence of brown pigmented colonies that gradually changed its color to black (melanin formation) was indication of tyrosinase positive organism. (Gare and Kulkarni, 2015)

\section{Peptone Yeast Extract Iron Agar}

The isolates were streaked on Peptone yeast extract iron agar ( $\mathrm{pH}$ 6.7) containing Peptic digest of animal tissue-1.5\%, Protease peptone- $0.5 \%$, Yeast extract- $0.01 \%$, Ferric ammonium citrate-0.005\%, K2HPO4-0.1\%, sodium thiosulphate- $0.008 \%$ and Agar-2\%. Plates were incubated at $30^{\circ} \mathrm{C}$ for $48 \mathrm{hrs}$ to observe brown pigmented colonies that gradually changed its color to black were indication of tyrosinase positive organism. (Gare and Kulkarni, 2015)

\section{Tyrosine Broth}

The isolates were inoculated into $50 \mathrm{~mL}$ of $0.1 \%$ tyrosine broth with few drops of Chloroform in $100 \mathrm{~mL}$ Erlenmeyer flask and incubated at $30^{\circ} \mathrm{C}$ for $48 \mathrm{hrs}$. The deep red color shows the positive results. (Gare and Kulkarni, 2015)

\section{MICRO-IS Identification of Actinomycetes}

Microscopic and cultural characteristics of isolates were initially helpful to identify actinomycetes upto genus level. Species level identification of actinomycetes were carried out by using their biochemical and 
other characteristics. Members of Streptomyces genus were used to identify isolates to species level by using PIBWin software. (Bryant, 2004) The software is modification of the DOS based software MICRO-IS. (Portyrata and Krichevsky, 1992) Probabilistic identification matrices used were Streptomyces species major cluster (Williams, et al., 1983; Williams, et al., 1985) and Streptomyces species minor cluster (Langham, et al., 1989) and for Streptoverticillium species (Williams, et al., 1985). Isolates belonging to other genera were identified manually (Langham, et al., 1989).

\section{Results and Discussion}

\section{Isolation and Identification of Actinomycetes}

A total 70 actinomycete isolates were obtained from different soil environments. Among 70 isolates, 18 isolates from soil of college region, 17 isolates from fertile soil of Shirala, 9 isolates from Sarud, 12 isolates from garden region of college and 14 isolates from Kokrud region. Out of 70 isolates studied 65 isolates were identified up to species level while remaining 05 were identified up to genus level. Among the total identified Streptomyces, maximum 12 isolates were Streptomyces lydicus followed by 11 Streptomyces chattanoogensis and 7 Streptomyces rimosus and Streptoverticillium olivoverticillatum each. Streptomyces cyaneus and Streptomyces luridus each 4, Streptomyces canus and Streptomyces xanthochromogenes each 3, Streptomyces cellulosae and Streptomyces varsoviensis each 2, Streptomyces albus, Streptomyces aurantiacus, Streptomyces californicus, Streptomyces chromofuscus, Streptomyces chromogenus, Streptomyces griseoluteus, Streptomyces phaeochromogenes and Streptomyces violaceus each 1(Table.1).

Table.1 Isolate Wise Identification of Actinomycete

\begin{tabular}{|c|l|c|}
\hline Sr. No. & Streptomyces identified & No. of isolates \\
\hline 1. & Streptomyces lydicus & 12 \\
\hline 2. & Streptomyces chattanoogensis & 11 \\
\hline 3. & Streptomyces rimosus & 7 \\
\hline 4. & Streptoverticillium olivoverticillatum & 4 \\
\hline 5. & Streptomyces cyaneus & 4 \\
\hline 6. & Streptomyces luridus & 3 \\
\hline 7. & Streptomyces canus & 3 \\
\hline 8. & Streptomyces xanthochromogenes & 2 \\
\hline 9. & Streptomyces cellulosae & 2 \\
\hline 10. & Streptomyces varsoviensis & 2 \\
\hline 11. & Streptomyces violaceoniger & 1 \\
\hline 12. & Streptomyces albus & 1 \\
\hline 13. & Streptomyces aurantiacus & 1 \\
\hline 14. & Streptomyces californicus & 1 \\
\hline 15. & Streptomyces chromofuscus & 1 \\
\hline 16. & Streptomyces chromogenus & 1 \\
\hline 17. & Streptomyces griseoluteus & 1 \\
\hline 18. & Streptomyces phaeochromogenes & 1 \\
\hline 19. & Streptomyces violaceus & 5 \\
\hline 20. & Unidentified & $\mathbf{7 0}$ \\
\hline & Total & \\
\hline
\end{tabular}


Table.2 Tyrosinase Production Potential of Actinomycete

\begin{tabular}{|c|c|l|c|c|c|}
\hline Sr.No. & $\begin{array}{c}\text { Isolate } \\
\text { No. }\end{array}$ & \multicolumn{1}{|c|}{ Identification } & $\begin{array}{c}\text { Tyrosine } \\
\text { agar }\end{array}$ & PYIA & $\begin{array}{c}\text { Tyrosine } \\
\text { broth }\end{array}$ \\
\hline 1 & C7 & Streptomyces spp. & + & + & + \\
\hline 2 & C13 & Streptomyces chattanoogensis & + & + & + \\
\hline 3 & C15 & Streptoverticillium olivoverticillatum & + & + & + \\
\hline 4 & C16 & Streptomyces chattanoogensis & + & + & + \\
\hline 5 & C22 & Streptomyces cellulosae & + & + & + \\
\hline 6 & C24 & Streptomyces lydicus & + & + & + \\
\hline 7 & C30 & Streptomyces chattanoogensis & + & + & + \\
\hline 8 & C33 & Streptomyces californicus & + & + & + \\
\hline 9 & C39 & Streptomyces chattanoogensis & + & + & + \\
\hline 10 & S1 & Streptomyces sp. & + & + & + \\
\hline 11 & S3 & Streptomyces cyaneus & + & + & + \\
\hline 12 & S29 & Streptomyces cyaneus & + & + & + \\
\hline 13 & S30 & Streptomyces chattanoogensis & + & + & + \\
\hline 14 & S31 & Streptomyces cyaneus & + & + & + \\
\hline 15 & S32 & Streptomyces aurantiacus & + & + & + \\
\hline 16 & S33 & Streptomyces chattanoogensis & + & + & + \\
\hline 17 & Kd8 & Streptomyces spp. & + & + & + \\
\hline 18 & Kd14 & Streptomyces cyaneus & + & + & + \\
\hline 19 & Sd11 & Streptomyces chromogenus & + & + \\
\hline
\end{tabular}

*Where + = Pigmentation

70 isolates were classified in 5 different genera. These genera and percentages were recorded as Streptomyces $82.85 \%$, Streptoverticillum 10\%, Nocardia and Micromonospora each $2.8571 \%$ and Actinomadura $1.4285 \%$.

\section{Tyrosinase Producing Actinomycetes}

Out of 70, 19 actinomycete isolates were showed blackish brown pigmentation on tyrosine agar and Peptone Yeast Extract Iron Agar (Table.2) while deep red color were observed in the tyrosine broth. Out of the total 19 reported tyrosinase producers maximum were from genus Streptomyces followed by Streptoverticillum. Percentage of tyrosinase production after qualitative test was recorded as $27.1 \%$.
Gare and Kulkarni (2015) reported C7 as maximum tyrosinase producer and identified isolate $\mathrm{C} 7$ on the basis of morphological, cultural, biochemical and $16 \mathrm{~S}$ rRNA gene sequencing as Streptomyces luteogriseus.

Gare and Kulkarni (2015) carried out qualitative tests for pigment melanin by inoculating in tyrosine broth supplemented with traces of chloroform and incubating at $30^{\circ} \mathrm{C}$ for $48 \mathrm{hrs}$. Red color was reported in tyrosine broth indicated positive melanin production. On the basis of intensity of red color seen in the tyrosine broth $\mathrm{Kd} 8$ was selected for further study. Out of these isolates $\mathrm{Kd} 8$ isolate was identified on the basis of morphological, cultural, biochemical and 16S rRNA gene sequencing as Streptomyces bikiniensis. $0.8 \mathrm{gm} / 100 \mathrm{ml}$ 
pigment was extracted from peptone yeast extract iron agar. The antibacterial activity of pigment extracted from $\mathrm{Kd} 8$ has been investigated. The pigment from isolate $\mathrm{kd} 8$ showed inhibitory zone against Escherichia coli, Staphylococcus aureus, Bacillus species and Salmonella typhi.

Rao et.al., (2012) studied Streptomyces antibioticus based on biochemical tests like urease, phenol red fermentation, nitrate reduction, starch hydrolysis and gelatine given positive results and indole, methyl red vogues proskauer, citrate utilization, carbohydrate utilization, phenyl alanine deamination, casein hydrolysis, colloidal chitin hydrolysis and catalase test negative results indicated that presence of Streptomyces antibioticus and tyrosinase. The results obtained after comparative studies indicated that isolation media and methods used in the present study are not only simple and reliable for large-scale bacterial identification but at the same time are more cost effective compared to commercially available diagnostic kits. This newly isolated and characterized tyrosinase may have potential applications in organic synthesis due to its high activity and stability at typically denaturing conditions.

In conclusion, Samples collected from all soil environment showed maximum percentage of Streptomyces genera. The actinomycetes isolated from soil sample were found to be the potential producer of tyrosinase.

\section{Acknowledgement}

Researchers are thankful to the Principal of Shriman Bhausaheb Zadbuke Mahavidyalaya, Barshi Dist. Solapur for providing laboratory and library facilities to carry out this study.

\section{References}

Bahrim, G., Negoita, T.G.H. 2007. Streptomyces strains from east Antarctic soils as tyrosinase producer. VI Simposio argentine III latinoamericano sobre investigations antarcticas, 09: 10-14.

Berdy, J. 2005. Bioactive microbial metabolites. J. Antibiot., 58: 1-26.

Bryant, T.N. 2004. PIBWin - software for probabilistic identification. J. App. Microbiol., 97(6): 1326-7.

Claus, H., Filip, Z. 1988. Behaviour of phenoloxidases in the presence of clays and other soil-related adsorbents. App. Microbiol. Biotechnol.,. 28: 506511.

Das, S., Lyla, P.S., Khan, S.A. 2008. Distribution and genetic composition of culturable marine actinomycetes from the sediments of Indian Continental Slop of Bay of Bengal. Chin. J. Oceanol. Limnol., 26: 16677.

Dos Santos, V.P.S., Silvaa, L.M.C., Salgado, A.M., Pereira, K.S. 2013. Application of Agaricus bisporus extract for benzoate sodium detection based on tyrosinase inhibition for biosensor development. Chem. Engi. Transactions., 32: 66-70.

Gare, S.S., Kulkarni, S.W. 2015. Isolation and characterization of tyrosinase producing streptomyces luteogriseus. World J. Pharm. Research. 4(4): 1385-1395.

Gare, S.S., Kulkarni, S.W. 2015. Lab scale production and antibacterial potential of melanin from Streptomyces Bikiniensis. Int. J. Pharm. Bio. Sci., 6(4): (B) 848-858.

George, M., Anjumol, A., George, G., Mohamed Hatha, A.A. 2012. Distribution and bioactive potential of soil actinomycetes from different 
ecological habitats. Afr. J. Microbiol. Res., 6: 2265-71.

Goodfellow, M., Williams, S.T., 1983. Ecology of Actinomycetes. Annu. Rev. Microbiol., 37: 189-216.

Gradilone, A., Cigna, E., Agliano, A.M., Frati, L. 2010. Tyrosinase expression as a molecular marker for investigating the presence of circulating tumor cells in melanoma patients. Curr. Cancer Drug Targets, 10: $529-538$.

Jawaid, S., Khan, T.H., Osborn, H.M.I., Williams, N.A.O. 2009. Tyrosinase activated melanoma prodrugs. AntiCancer Agents in Med. Chemistry, 9: 717-727.

Kong, K.H., Hong, M.P., Choi, S.S., Kim, Y.T., Cho, S.H. 2000. Purification and characterization of a highly stable tyrosinase from Thermomicrobium roseum. Biotechnol. Appl. Biochem., 31: $113-118$.

Korn-Wendisch, F., Kutzner, H.J. 1992. The family Streptomycetaceae. In: Balows A, Truper HG, Dworkin M, Harder W, Schleifer KH, Editors. The Prokaryotes, New York: SpringerVerlag Inc. 921-95.

Kuster, E. 1968. Taxonomy of soil actinomycetes and related organisms. In: Gray S, Parkinson T, Editors. Ecology of soil bacteria. Liverpool, Liverpool University Press.

Langham, C.D., Williams, S.T., Sneath, P.H.A., Mortimer, A.M. 1989. New probability matrices for identification of Streptomyces. J. General Microbiol., 35: 121-133.

Lechevalier, H., Lechevalier, M.P. Introduction to the order actinomycetales. In: Starr MP, Stolp H, Truper HG, Balows A, Schlegel HG.(1981). Editors, The prokaryotes, Germany, Springer-verlag Berlin, 2: 1915-22.
Monogioudi, E., Faccio, G., Lille, M., Poutanen, K., Buchert, J., Mattinen, M.L. 2011. Effect of enzymatic crosslinking of $\beta$-casein on proteolysis by pepsin. Food Hydrocolloids, 25: 7181.

Portyrata, D.A., Krichevsky, M.I. 1992. MICRO-IS, A microbiological database management and analysis system. Binary, 4: 31-36.

Rao sambasiva, K.R.S., Tripathy, N.K., Mahalaxmi, Y., Prakasham, R.S. 2012. Biochemical characterization and identification of extracellular biosynthesis in Streptomyces antibioticus. Int. Res. J. Biochem. Bioinformatics, 2(4): 90-92.

Robb, D.A. 1984. Tyrosinase in Copper Proteins and Copper Enzymes. CRC Press Boca Raton Fla., R Lontie Ed: 207-241.

Sprusansky, O., Stirrett, K., Skinner, D., Denoya, C., Westpheling, J. 2005.The bkd R gene of Streptomyces coelicolor is required for morphogenesis and antibiotic production and encodes a transcriptional regulator of a branched chain amino acid dehydrogenase complex. J. Bacteriol., 187: 664-71.

Srinivasan, M.C., Laxman, R.S., Deshpande, M.V. 1971. Physiology and nutrional aspect of actinomycetes- An overview. World J. Microbial. Biotechnol., 7: 171-84.

Ventura, M., Canchaya, C., Tauch, A., Chandra, G., Fitzgerald, G.F., Chater, K.F. 2007. Genomics of actinobacteria: Tracing the evolutionary history of an ancient phylum. Microbiol. Mol. Biol. Rev., 71: 495-548.

Wang, G., Aazaz, A., Peng, Z., Shen, P. 2000. Cloning and overexpression of a tyrosinase gene mel from Pseudomonas maltophila. FEMS Microbiol. Lett., 185: 23-27. 
Whitaker, J.R. 1995. Polyphenol oxidase in food enzymes: structure and mechanism. Chapman and Hall New York NY USA, D.W. S. Wong Ed, 271-307.

Williams, S.T., Goodfellow, M., Wellington, E.M.H., Vickers, J.C., Alderson, G., Sneath, P.H.A., Sackin, M.J., Mortimer, A.M. 1983. A probability matrix for identification of some Streptomycetes. J. General Microbiol. 129: 1815-1830.
Williams, S.T., Locci, R., Vickers, J.C., Schofield, G.M., Sneath, P.H.A., Mortimer, A.M. 1985. Probabilistic identification of Streptoverticillium species. J. General Microbiol.,131: 1681-1689.

Williams, S.T., Sharpe, M.E., Holt, J.G. 1989. Bergey's Manual of Systematic Bacteriology. Williams and Wilkins, London, 4.

\section{How to cite this article:}

Gare Sandip Subhash, Karad, D.D. and Kulkarni, S.W. 2016. Screening of Tyrosinase Producing Soil Actinomycetes from Shirala Region of Maharashtra, India. Int.J.Curr.Microbiol.App.Sci. 5(3): 345-353. doi: http://dx.doi.org/10.20546/ijcmas.2016.503.041 